\title{
Benign joint hypermobility syndrome
}

\author{
Sigrid Covaci ${ }^{1,2,3}$, Oana-Maria Farkas ${ }^{1,4}$, Alexis-Virgil Cochino ${ }^{1,2}$ \\ 1"Alessandrescu-Rusescu" National Institute for Mother and Child Health, Bucharest, Romania \\ 2"Carol Davila" University of Medicine and Pharmacy, Bucharest, Romania \\ 3"Sf. Maria" University Hospital, Bucharest, Romania \\ 4"Dr. I. Cantacuzino" University Hospital, Bucharest, Romania
}

\begin{abstract}
Musculoskeletal pain is the most common cause of presentation in rheumatology service. Most frequent causes of joint pain are noninflammatory conditions, with benign joint hypermobility syndrome (BJHS) being one of them. BJHS is not an actual disease but an inherited variation of normal. Some clinical features of this syndrome can lead to confusion with Juvenile Idiopathic Arthritis (JIA) and therefore to unjustified treatment, which makes its recognition mandatory. A case of BJHS in a 11-year-old girl is presented; the patient was initially diagnosed as JIA and received immunosuppressive treatment for 2 years.
\end{abstract}

Keywords: musculoskeletal pain, benign joint hypermobility syndrome, children

\section{INTRODUCTION}

Musculoskeletal pain is the most common cause of presentation in rheumatology service. Most frequent causes of joint pain are noninflammatory conditions, with benign joint hypermobility syndrome (BJHS) being one of them. This syndrome is characterized by hypermobility of the joints associated with musculoskeletal chronic pain, subluxation, soft tissue lesions, marfanoid habitus and skin manifestations. BJHS is not an actual disease but an inherited variation on normal (1) defined by a greater range of motion in the joints of the limbs and spine. The joint laxity is higher in children and diminishes gradually during adolescence; females also have greater degree of joint laxity (2). It seems as a frequent cause of joint pain, as a study found that $66 \%$ of school children with arthralgia of unknown etiology had joint hypermobility (3). On the other hand, there are healthy individuals with generalized joint laxity and no complain.

Although BJHS itself is an inoffensive condition, it is sometimes associated to conditions with joint hypermobility, abnormal skin features and chronic joint/extremity pain, e.g. Ehlers-Danlos syndromehypermobility type (4). Joint hypermobility can also be prominent in other different forms of heritable disorders of connective tissue (such as Marfan syndrome or Osteogenesis imperfecta), chromosomal and genetic disorders (e.g. Down syndrome, Williams syndrome) and in some metabolic disorders (e.g. homocystinuria and hyperlysinemia) (5).

BJHS has a strong genetic component, most frequently with an autosomal dominant pattern, firstdegree relatives with this syndrome being identified in up to $50 \%$ of cases (5). Some data suggest X-linked defects, involving genes that encode for connective tissue matrix proteins such as type I, III and V collagen, elastin and fibrillin, as well as the extracellular matrix glycoprotein tenascin, which can be involved in a loss of resistance to stretching of the tissues surrounding joints (6).

Children with BJHS most frequently complain of joint pain, following physical activities or sports. Generally, pain is self-limiting but it sometimes lasts months or even years. Morning stiffness is not a feature of BJHS.

In 1964 Carter and Wilkinson developed the first criteria used for diagnosing BJHS; at present, most physicians use the Brighton criteria (Table 2) developed in 1998 by the British Society for Rheumatology Special Interest Group on Heritable Disorders of Connective Tissue, utilizing the nine-point Beighton scale (Table 1). 


\section{TABLE 1. Beighton scale}

\begin{tabular}{|l|}
\hline $\begin{array}{l}\text { Passive dorsiflexion of the fifth metacarpophalangeal joint to } \\
\text { at least } 90^{\circ} \text { (Fig. 1) }\end{array}$ \\
\hline $\begin{array}{l}\text { Passive opposition of the thumb to the volar aspect of the } \\
\text { ipsilateral forearm (Fig. 2) }\end{array}$ \\
\hline Active hyperextension of the elbow to at least $10^{\circ}$ \\
\hline Active hyperextension of the knee to at least $10^{\circ}$ \\
\hline $\begin{array}{l}\text { Lumbopelvic forward flexion with placement of hands flat on } \\
\text { the floor without bending the knees }\end{array}$ \\
\hline
\end{tabular}

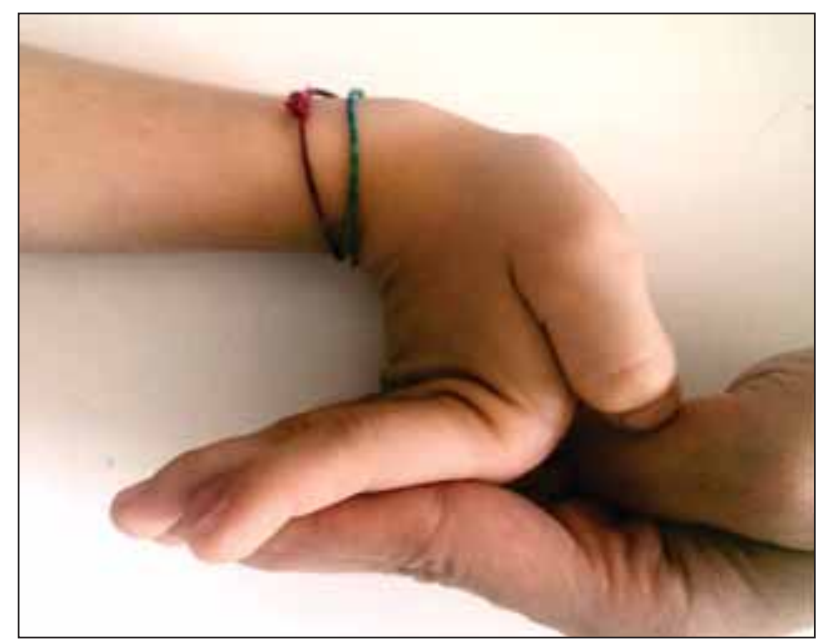

FIGURE 1. Passive dorsiflexion of the fifth metacarpophalangea

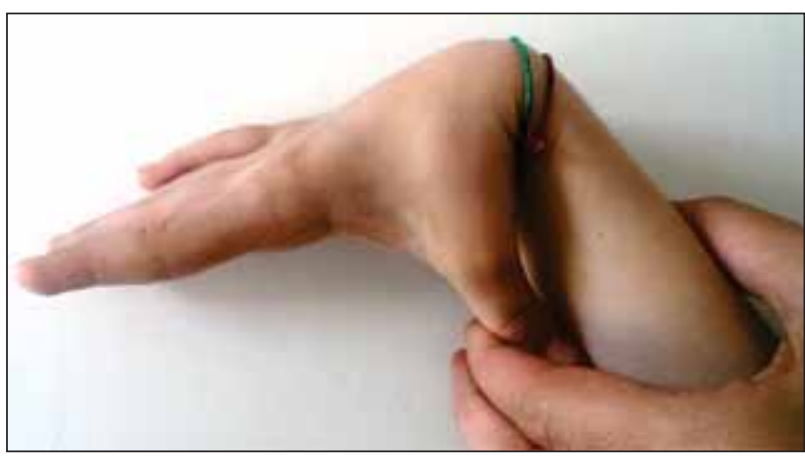

FIGURE 2. Passive opposition of the thumb to the volar aspect of the ipsilateral forearm (personal archive)

One point is gained for each side of the body for the first four maneuvers listed above, such that the maximum hypermobility score is 9 .

BJHS is diagnosed in the presence of 2 major criteria, one major criteria plus 2 minor criteria, or 4 minor criteria. Diagnosis can be based on only $2 \mathrm{mi}-$ nor criteria if there is an unequivocally affected first-degree relative in family history. The syndrome is excluded by the presence of Marfan or Ehlers-Danlos syndrome (other than the hypermobility type of Ehlers-Danlos syndrome).

Children with hypermobility can present other noncriteria features, such as the ability to put heels behind head, excessive internal rotation of the hip,
TABLE 2. Brighton criteria

\begin{tabular}{|l|}
\hline Major criteria \\
\hline Beighton score of $\geq 4$ \\
\hline Arthralgia for longer than 3 months in 4 or more joints \\
\hline Minor criteria \\
\hline Beighton score of 1, 2 or 3 \\
\hline $\begin{array}{l}\text { Arthralgia (> } 3 \text { month duration) in 1-3 joints or back } \\
\text { pain (> } 3 \text { month duration) or spondylosis, spondylolysis/ } \\
\text { spondylolisthesis. }\end{array}$ \\
\hline $\begin{array}{l}\text { Dislocation or subluxation in more than one joint, or in one } \\
\text { joint on more than one occasion. }\end{array}$ \\
\hline $\begin{array}{l}\text { Three or more soft tissue lesions (e.g. epicondylitis, } \\
\text { tenosynovitis, bursitis) }\end{array}$ \\
\hline $\begin{array}{l}\text { Marfanoid habitus (tall, slim, arm span greater than height [> } \\
1.03 \text { ratio], upper segment less than lower segment (<0.89 } \\
\text { ratio), arachnodactyly) }\end{array}$ \\
\hline Skin striae, hyperextensibility, thin skin, or abnormal scarring \\
\hline Ocular signs: dropping eyelids, myopia, antimongoloid slants \\
\hline $\begin{array}{l}\text { Varicose veins, hernia, uterine or rectal prolapse, mitral valve } \\
\text { prolapse }\end{array}$ \\
\hline
\end{tabular}

excessive ankle dorsiflexion, excessive eversion of the foot or passive elbows touch behind the back (4).

\section{CASE REPORT}

A 14 years old female patient presents for second opinion in November 2014, having been previously diagnosed with JIA.

Disease onset was in June 2011 (11 years old) with left knee pain and impaired gait over approximately seven days which was resolved without treatment. In January 2012 the patient accuses bilateral heel pain with tip toes walking, lasting 2-3 days, repeated within the next 3 weeks. In May 2012, pain and swelling in the left ankle occur; joint was immobilized 7 days in a cast but, as symptoms persisted, she was referred to a pediatric rheumatology clinic. Physical examination revealed at that time a healthy girl, with normal development and nutritional status $(28 \mathrm{~kg}, 125 \mathrm{~cm})$, and swollen left ankle. Routine blood tests and eye exam were normal. Patient was discharged on NSAIDs. After a month, she was reevaluated and the diagnosis of JIA - enthesitis related arthritis (ERA) was made, based on clinical examination findings (mild swelling of left ankle and enthesitis - patellar tendon, Achilles tendon, superior anterior and posterior iliac spines) and she was started on sulfasalazine (SSZ). After 4 month of treatment with SSZ, clinical examination reveals the absence of patellar and Achilles reflexes and neurological examination suspected a polyneuropathy; as this was viewed as a potential SSZ side effect, patient was switched to methotrexate (MTX). 
After 18 months of methotrexate treatment she presented to the National Institute for Mother and Child Health "Alessandrescu-Rusescu" for multiple joints pain. During her 3 years of disease evolution she never presented raised inflammatory markers and was repeatedly negative for rheumatoid factor (FR) and antinuclear antibodies (ANA); HLA B-27 is also absent. At history, the patient's mother reported repeated sprains, dislocations and fractures ("she broke all of her hand and foot bones"), for which the patient was evaluated in orthopedics service. Clinical examination showed no sign of arthritis but the presence of hypermobility in many joints, with a Beighton score of 9/9. Based on medical history (multiple dislocations and "fractures", persistent joint pain despite treatment), clinical findings (Beighton score of 9/9 - same in her mother), normal investigations, diagnosis of JIA was refuted and replaced by BJHS, patient fulfilling 2 major criteria. Other connective tissue conditions with joint hypermobility were excluded, as patient's skin texture was normal and she had no clinical features of Ehlers Danlos or Marfan syndromes. Treatment was stopped and patient was recommended a training program for muscle strength improvement, joint elastic bands wearing and contact sports avoidance.

\section{DISCUSSIONS}

A case of BHJS is presented, initially diagnosed as JIA and treated with NSAIDs and DMARDs. At 3 years reevaluation, after repeating history and physical examination, BJHS replaced the JIA diagnosis. As such, we stress the importance of history taking and clinical examination.

\section{REFERENCES}

1. Thomas J.A. Lehman. A clinician's guide to rheumatic disease in children. New York, Oxford University Press, 2009.

2. Gaurav Solanki, Namita Lohra, Jaya Lohra, Renu Solanki. A case reporting benign hypermobility syndrome. Journal of Advanced Nursing Practice. 2014;1(1):7-9.

3. Gedalia A., Brewer E.J. Joint hypermobility in pediatric practice a review. J Rheumatol. 1993; 20:371 -374.

4. Claire LeBlanc and Kristin Houghton in Textbook of pediatric rheumatology, 6th Ed - Philadelphia, PA: Elsevier/Saunders, 2011

5. MAJ Michael R. Simpson, Benign Joint Hypermobility Syndrome: Evaluation, Diagnosis, and Management in The Journal of the
Although there are few case reports of BJHS coexisting with different subtypes of JIA, no JIA criteria was fulfilled in our patient and, moreover, arthralgia persisted despite treatment. The so-called enthesitis she presented could be explained by psychic conversion, validated by psychologist. Mild joint effusions may be observed in children with BJHS, and it was also present in our case, diverting the diagnosis from BJHS towards JIA.

Joint hypermobility is common amongst children but only a minority develop symptoms and signs that characterizes BJHS; consequently, a high Beighton score does not mean BJHS (7).

This excessive mobility can be sometimes beneficial for children practicing certain sports (e.g. ballet or gymnastics) but it can sometimes cause joint pain (especially after overstressing) or even injury, such as recurrent dislocations.

\section{CONCLUSIONS}

The diagnosis of BJHS is based on history and clinical evaluation, after excluding other differential diagnoses such as polyarthralgia, different forms of heritable disorders of connective tissue, genetic or metabolic disorders.

This diagnostic recognition is important in order to avoid inappropriate treatment; in a child with hypermobility, one must not omit diseases with potentially serious complications such as Ehlers Danlos syndrome or Marfan syndrome.

Once diagnosis is made, management is mainly based on training programs for muscle strength improvement, joint elastic bands wearing and contact sports avoidance. NSAIDs may be used for a few days for pain relief.

Conflict of interest: none declared Financial support: none declared

American Osteopathic Association, September 2006, Vol. 106, 531-536.

6. Malfait F., Hakim A.J., De Paepe A., Grahame R. The genetic basis of the joint hypermobility syndromes. Rheumatology (Oxford) 2006; 45: 502-507

7. Carmen Tsz-Kwan Ho, Case Report - Benign Joint Hypermobility Syndrome in Hong Kong Bulletin on Rheumatic Diseases, Volume 6, No. 2, December 2006 